Bashir Salah

Sajjad Khan

Nikola Gjeldum

https://doi.org/10.21278/TOF.44206

ISSN 1333-1124

eISSN 1849-1391

\title{
AN AUTOMATIC YOGURT FILLING SYSTEM BUILT FROM SCRATCH BASED ON INDUSTRY 4.0 CONCEPT
}

\begin{abstract}
Summary
The movement to digitally transform Saudi Arabia in all sectors has already begun under the focused "Vision 2030" programme. Consequently, the task of renovating and standardizing manufacturing and other production industries to compete with global challenges is essential. The fourth industrial revolution (Industry 4.0), triggered by the development of information and communications technologies (ICTs), provides a basis for smart automation using decentralized control and advanced connectivity (e.g., Internet of Things). In the areas where the spirit of Industry 4.0 has been embraced, some industries have already implemented these ideas and yielded gains. Learning the principles of Industry 4.0 and having knowledge of this digital industrial revolution is essential for future engineering graduates. In this paper, a case study on building a learning factory from scratch based on the concept of Industry 4.0 is introduced. The initial achievement of a fully automated production line is presented. In doing so, a system with a smart design having smart control and smart monitoring is developed.
\end{abstract}

Key words: $\quad$ learning factories, engineering education, smart control, smart monitoring, industry 4.0

\section{Introduction}

The Industry 4.0 concept pilots a new stage for industrial production processes, where the Internet of Things (IoT), Internet of Data, Internet of Services (IoS) and Internet of People are recognized [1]. "Vision 2030" was launched by the Kingdom of Saudi Arabia (KSA) to digitally transform its industries and economics. Also, it initiated the expansion of industrial capabilities to meet the objective of Industry 4.0 [2]. Thus, it is essential to renovate and standardize our production and manufacturing industries to respond to the global challenges. Industry 4.0 is an arena for innovators and will provide a technological level playing field for small and medium-sized enterprises (SMEs), micro-, small- and medium-sized enterprises (MSMEs) and corporations to implement its principles. Industry 4.0 can be defined as the usage of real time captured data from smart objects in manufacturing processes for real time monitoring, analysing, and consequently control. The interaction between smart objects and the manufacturing process through the internet allows decisions to be made quickly and efficiently [3]. In the same context, several definitions for Industry 4.0 can be found [4]. 
Industry 4.0 is considered to be the most important technology innovation as it enables end users (customers) to receive their products based on their expectations in terms of product variety and quality (i.e. mass customization).

Due to the fast pace of technological innovation, it is essential for the Industrial Engineering Department (IED) graduates at King Saud University (KSU) to learn new concepts and handle highly sophisticated industrial machinery in order to achieve future success as entrepreneurs. Our dedicated faculty team of IED/KSU recognized the importance and hence directed one of our research wings to focus their efforts on the collaboration with budding engineering graduates. With the introduction of the $5 \mathrm{G}$ technology to the KSA, we are convinced that our work will get out of the lab to real-world applications and will have an immense impact. In the KSA, we recognize the importance of renovating and standardizing manufacturing industries in order to respond to global challenges and consider this to be an essential element of "Vision 2030".

In this study, a student research group work motivated by the I4.0 orientation programme initiated a process of building a prototype fully automated production plant from scratch (Fig. 1). The core principle was to focus on building a state-of-the-art technological production plant based on the principles of I4.0 for manufacturing a smart product. The team established the essential factors and stages required to accomplish this task. Initially, a brainstorming session regarding the strengths of our existing hardware was performed, and the new equipment to be procured was listed.

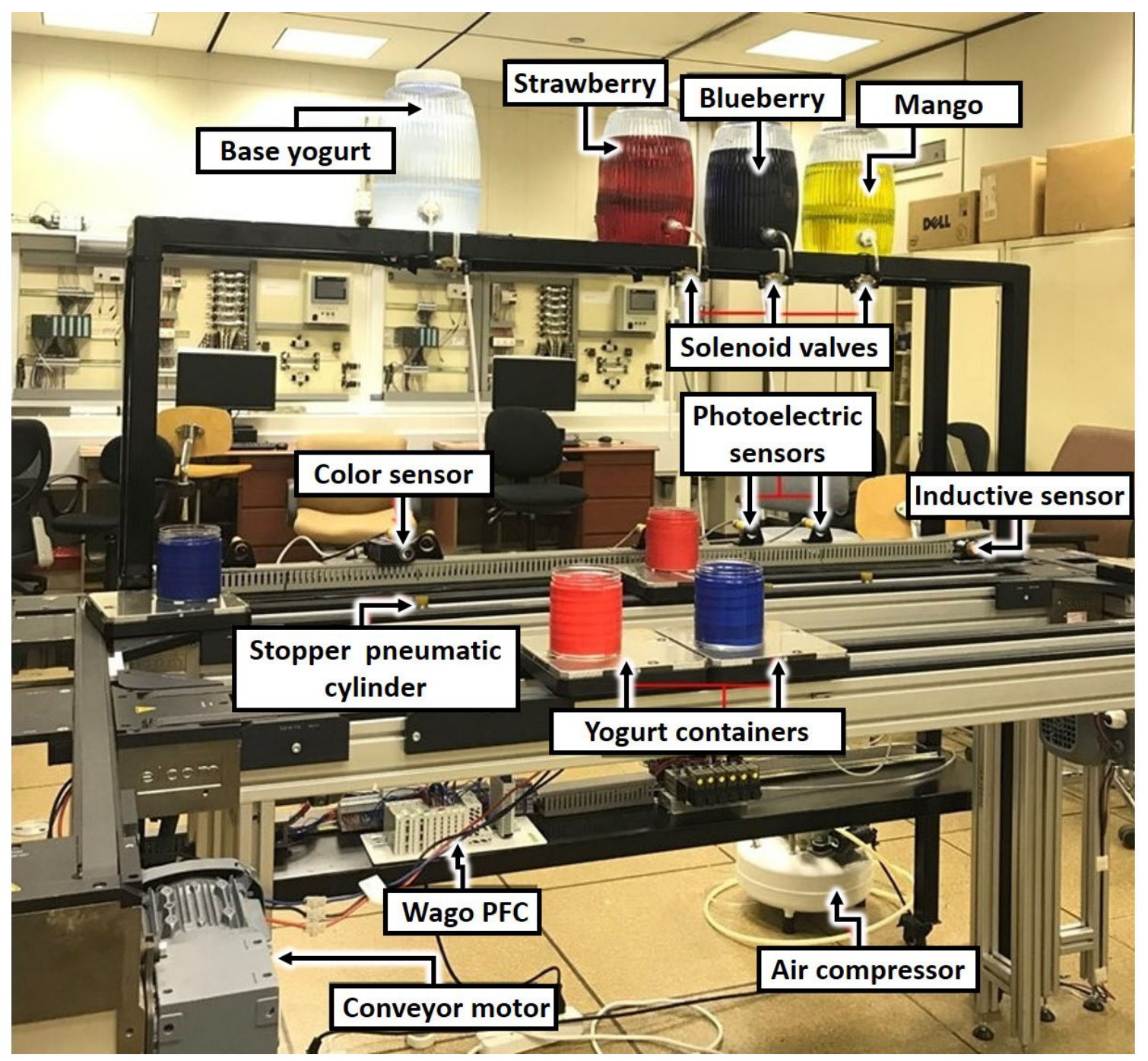

Fig. 1 Basic design of a smart production plant 
In this scenario, a mass customized production facility in a single chain to manufacture flavoured yogurt was to be built to demonstrate the Industry 4.0 concept. The facility comprises an automated three-flavour yogurt filling machine built from scratch and integrated digitalization and networked production techniques, including packing and storing in a refrigerated storage and retrieval system. The project was not simply to procure and assemble available equipment but to establish a systematic approach where we incorporate I4.0 principles such as additive manufacturing (3D printing), an Industrial Internet of Things (IIoT) sensor, autonomous robots etc. We overcame barriers existing in a production facility by modifying available devices, adapting appropriate communication subsystems and bridging the manufacturer-client relationship with the latest technology. As can be seen in Fig. 1, a prototype was designed to have data driven execution where the product interacts with the production plant machinery at every stage of its development.

\section{Literature review}

Presently, engineering laboratories have to be designed in such a way as to be able to face continuous changes in market requirements $[5,6,7]$. Changes are due to several factors, including the dynamic nature of the market, remarkable advances in automation, ICT, and partly due to the evolution of requirements for ever more sophisticated and customized products. Such requirements often imply the need for highly sophisticated production systems and operations for products to be designed, developed and manufactured to meet the market demand by combining the flexibility and personalization of custom-made products with low unit costs associated with mass production [8]. In this context, educational institutions have to develop engineering laboratories that take advantage of available technologies and recent technological advances to teach and train senior engineering students in what is called learning factories (LF). The aim of LFs is to provide students with the knowledge and skills required to design and operate sophisticated manufacturing systems.

Recently, the concept of LF-based Industry 4.0 has been introduced to revolutionize the engineering learning process and to make training procedures more realistic [9]. For instance, several learning factories can be identified in the literature which takes the role of teaching, training and/or research in the field of Industry 4.0. The Institute of Industrial Manufacturing and Management (IFF) at the University of Stuttgart developed a LF for advanced industrial engineering which combines a digital learning environment and a physical model factory to provide an integrated approach [10]. Similarly, ElMaraghy et al. [11] introduced a LF that integrates the product development process, operation, and control. Schreiber et al. [12] introduced a research-based learning concept that allows students to explore their own research questions and teaches them how to solve these problems using scientific methods. However, the concept was designed and utilized like a research project rather than as a teaching tool for senior engineering students. Although several researchers have addressed LFs in the engineering education context, there are only very few educational institutions that have actually implemented LFs in their system as a teaching method for senior engineering students [9].

While numerous learning factories have been built in industry and academia in the last decade, comprehensive, applied and focused practical training is still missing [13]. Considering the importance of such training, an automated production line for real-life applications supported by Industry 4.0 technologies had to be built at the University of King Saud to provide senior graduate students with hands-on experience. A plan was therefore 
developed to build a sophisticated system with high standards of programming language (IEC 61131-3), communication sub-systems (IEC 61131-5) controlled by the soft PLC software, along with cyber-physical systems (CPS).

Two different approaches to the design of control mechanisms of real time computer applications can be identified, depending on the type of the triggering mechanism used: a) time-triggered control, and b) event-triggered control [14]. In the time-triggered control, all activities are initiated by the progression of real time. In the event-triggered control, all communication and processing activities are initiated whenever a significant event other than the regular event of a clock tick occurs [15].

In this project, the main objective of the development of a production line for filling yogurt with different flavours is to aid students in understanding the complexities of the design, monitoring, operation and control of the production line. The developed system allows the user to operate it from any location since it uses the internet to connect with the computer. Moreover, the project shows how a process has to be designed depending on programmable fieldbus controllers (PFC) in order to educate students in the complexity of designing, implementing and operating the yogurt filling system.

\section{Materials and methods}

In our Automation and Control Laboratory an existing conveyor system had to be repaired and permanently integrated with the upcoming modules of the production line. First, it was rearranged from an L to a U closed-loop configuration. From the beginning, there was rigid adherence to utilizing appropriate technologies from the I4.0 concept. Hence, the IEC 61131 standards for programming and communication subsystems were always maintained. For control systems that were geographically separated, intensive data transfer for an eventdriven execution system required an appropriate communication subsystem to ensure data consistency, data integrity and its coherence. An Ethernet IP communication subsystem satisfied the switch requirement using the IEEE-1588 technology to distribute clocks and synchronized time bases. In addition, we realized that in the I4.0 concept, the smart monitoring function demands the IEC 61131 standard because of its reliability in data encapsulation and because of its advanced architecture to support the event-driven execution of function blocks (FBs) and programs. This standard also explicitly refers to an important generic communication pattern Publish/ Subscribe (PUB/SUB) for unidirectional transactions which are required for intercommunication between different controllers via the internet.

\subsection{Challenges}

The first challenge was to repair the conveyor track where a specific component of the conveyor track was damaged, meaning that the base plate could not complete its closed-loop sequence. A similar component at the other end of the track was available, so a replicated piece had to be manufactured. Using the concept of additive manufacturing and the CATIA software, a precisely dimensioned component was made using a 3D printer. This replacement piece was made of polypropylene composite material. The 3D printed component (Fig. 2) was mounted on the conveyor system and operated as required. A detailed analysis of this first challenge will be elaborated in another paper yet to be published. 


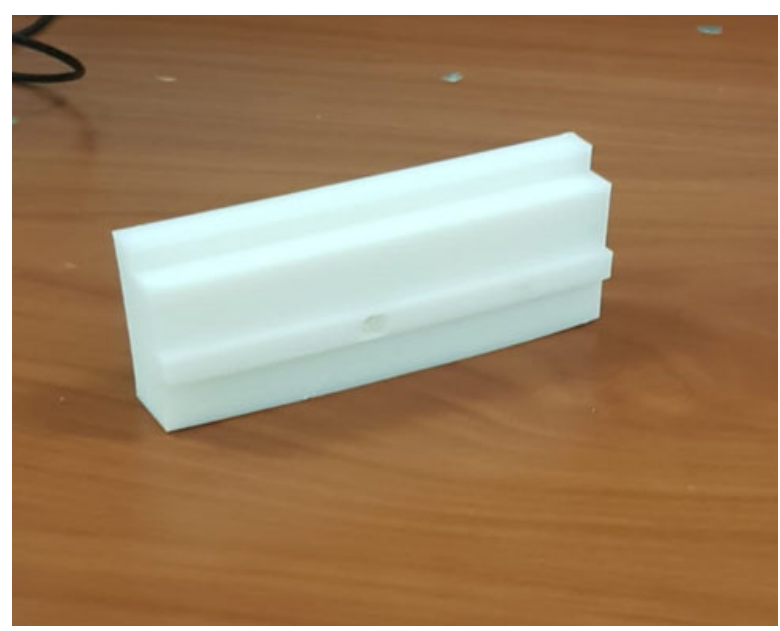

a)

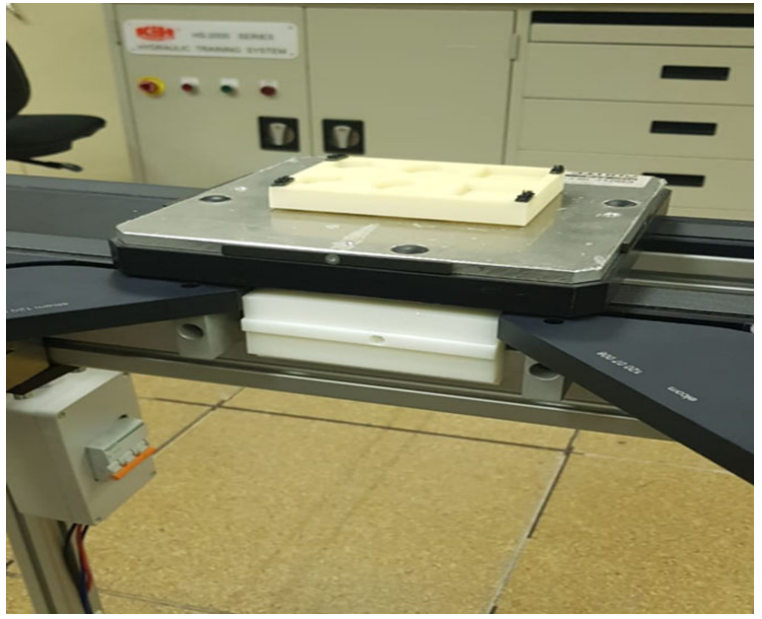

b)

Fig. 2 Defective conveyor component: a) 3D printed component, b) 3D printed component installed in conveyor system

The second challenge was the selection of appropriate field devices, such as sensors, solenoid valves, and pneumatic pistons. A variety of sensor types such as photoelectric, photo reflective, proximity, induction, contrast, and colour sensors were opted for and regarded as the eyes of the system. A WAGO programmable field controller (PFC) 750-8100 was procured due to its high-speed data processing with built-in OPC UA, web server, firewall and security features supporting its own IT infrastructure in remote applications.

To ensure that the host PC can communicate with the controller via Ethernet, both devices were located in the same subnet. The IP addressing adaptation of the system structure was done to ensure that the PC and the controller could communicate with one another using the web-based management (WBM) configuration tool.

The data from the sensors driving the work and operation flow was triggered by the occurrence of the defined events. The Ladder logic program in the Wago e-Cockpit software was written and downloaded onto the PFC. The web-based management (WBM) configuration was also enabled to allow the status of operation to be viewed online, and the hardware installation of the field devices was completed. Now every colour-coded product stores the product development data at every stage of production. The product communicates operational data and requirements which are stored directly as an individual building plan. In this way, the product itself requests the required resources and orchestrates the production processes for its completion. Within a smart factory, products can communicate with their environment and influence the arrangement of reconfigurable manufacturing systems (RMSs). The complexity of coordination can be reduced while increasing the flexibility by dividing the production process into small value-oriented units, which only share information regarding the consecutive process step. There are certain challenges in a semi-automated or fully automated production cycle. Challenges also depend on whether the process is event-driven or whether time-driven tasks are performed. It is essential for there to be an interaction between the production cycle modules and the customized products. A yogurt bottle to be filled is mounted on the base plate of the conveyor. When the start button is pressed, the base plate moving on the conveyor reaches the first slot and the yogurt base is filled. The base plate movement is paused with a pneumatic piston, and simultaneously the colour is detected by the colour sensor. After the colour has been recognized, the corresponding sensor detects the 
bottle and a piston stops the bottle at the desired flavour station. Once the desired yogurt flavour filling process finishes, the next empty bottle enters the process chain.

\subsection{Case study}

\subsubsection{Hardware description}

To gain practical experience in the principles of Industry 4.0, the IED/KSU team decided to build an industrial learning factory. This new initiative had to begin from scratch. The production line has different stages comprising typical applications such as conveying, identification, sorting of flavours, and filling of a liquid defined by users.

This automatic yogurt filling system was built with an automation solution using a Wago 750-8202 programmable field bus controller (PFC 200) and programmed in the eCockpit software using the standard IEC 61131. Our initial study showed that relatively sophisticated control software was required because the initial goal was to establish a fully independent automated production line synchronizing various tasks from different controllers. The modular design of hardware (connected by Ethernet/IP) and corresponding control modules was realized at every stage, and significant clarity and maintainability of the programs was supported by using only the IEC standards. Precautionary and safety measures were added as a programming function to halt the process so as to avoid any accidents when it would be implemented in an industrial environment.

\subsubsection{Production process}

The system consists of three stages. Initially, empty bottles stacked on the base plate on the conveyor belt are fed one by one into the production line using the pneumatic piston. Fig. 3 shows the process which begins when the "START" button is pressed and the presence of a bottle is detected on the base plate. The first event is initiated and on the high precision arrival of the base plate to the base yogurt filling section, three tasks swiftly occur. First, the base plate on the conveyor belt is stopped by up-lifting the pneumatic piston. A solenoid valve is then opened for a defined time interval to fill up the required quantity of base yogurt. In the third task, the colour of the arriving bottle is identified by photoelectric contrast. The data from the colour sensor is used to initiate the next event of filling the user-defined flavour. The data obtained by the colour sensor is shared as a global variable with the next stages of the production. After the bottle is filled with a specified quantity of base yogurt, the pneumatic piston goes down and the base plate proceeds to the next step. 


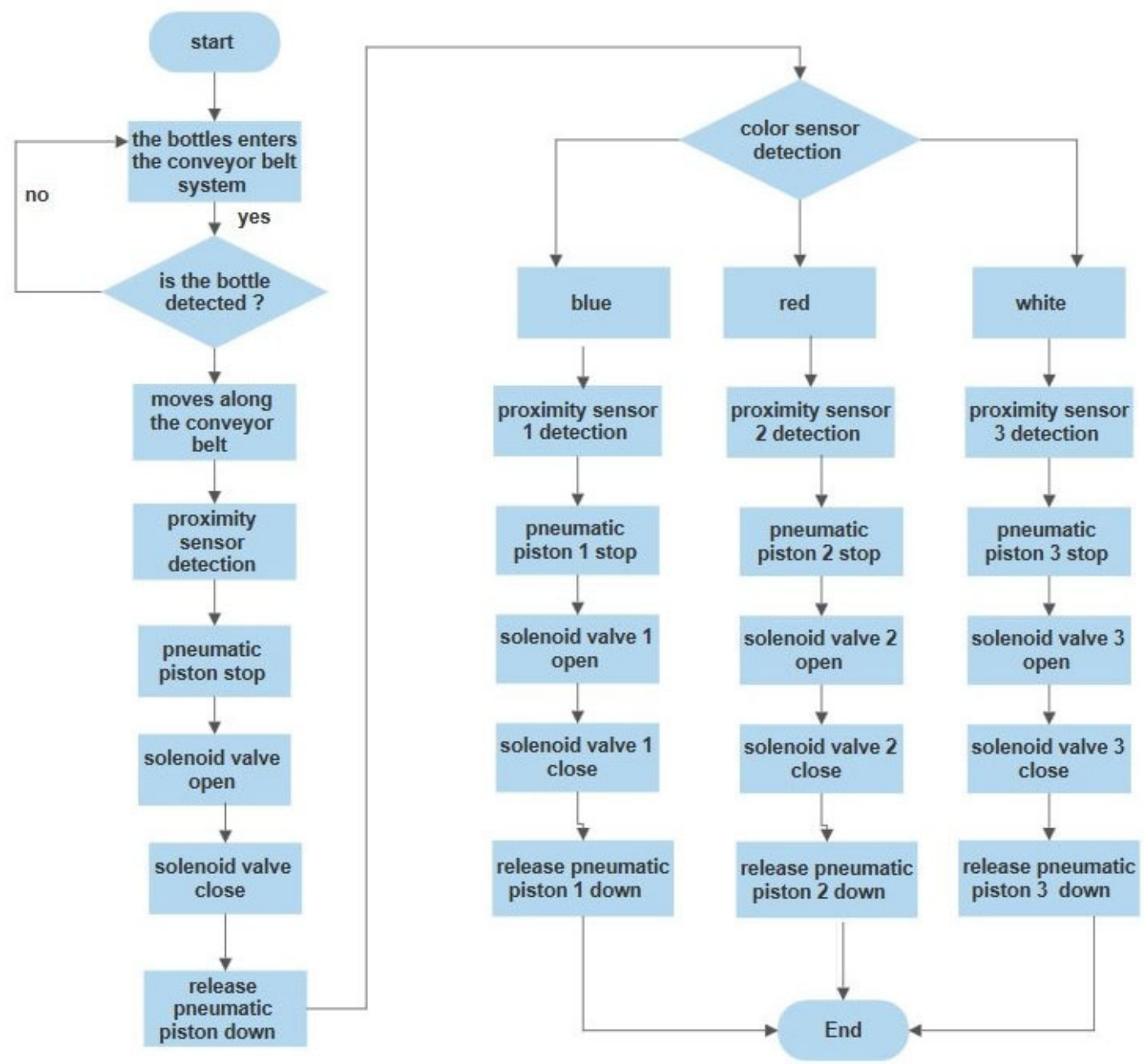

Fig. 3 Operational sequence flowchart

The next event occurs only at the specified flavour section, based on the data received from the sensor. The base plate is stopped at a precise position by a pneumatic piston to allow the bottle to be filled up with the user-defined flavour. There are three different yogurt flavours, strawberry, blueberry and mango flavour. Subsequently, the desired yogurt flavour is added by the opening of the solenoid valve. After the filling process is completed, the corresponding pneumatic piston goes down and the filled bottle is transported to the end of the conveyor. The proximity sensor installed at the end of the conveyor initiates the next event, which is the transporting of the filled yogurt bottles to the corresponding position in the refrigerated warehouse by a robotic arm.

\section{Results and discussion}

The outcomes of the first stage are containers filled with various combinations of userdefined flavour and base yogurt. Three predominant objectives are achieved in the first phase, (1) smart design, (2) smart monitoring and (3) smart control. The technology utilized in the presented fully automated production learning factory can be applied to industrial production plants that have mass customization capabilities. As mentioned in the previous sections, this beginning phase of our project executes the operation with a single programmable field controller. The next phase will focus on the synchronization of multiple controllers performing multiple tasks, driven by data on event occurrence. They will perform parallel operations where the controller analysis of execution time, idle state and sleep time is carried out. 


\subsection{System indicator}

The first phase of the building of our learning factory based on the Industry 4.0 concept was completed. Its function was tested and its performance results were compared with our existing production line prototype. The number of yogurt bottles filled in different types of manufacturing processes was compared, such as job shop, discrete and repetitive manufacturing. The results of the comparison were analysed. In the repetitive and mass production, a large quantity and less variety of products were obtained. In the discrete and job shop manufacturing, a variety of products with a reduced quantity was obtained as opposed to the former manufacturing type. Our attempt was also to address this challenge and overcome the related real time issues. The presented automated learning factory can be programmed to deliver products using few types of manufacturing processes such as repetitive, discrete and the Industry 4.0 concept (enabled smart monitoring, smart controlling). The time required to deliver a filled yogurt bottle with desired customer-defined flavour was computed (Fig. 4). An important system indicator of utilising the additive manufacturing process in building our learning factory is elaborated in Chapter 3.1. This indeed establishes the influence of the Industry 4.0 concept in manufacturing and repairing the production lines halting operation due to minor hardware problems.

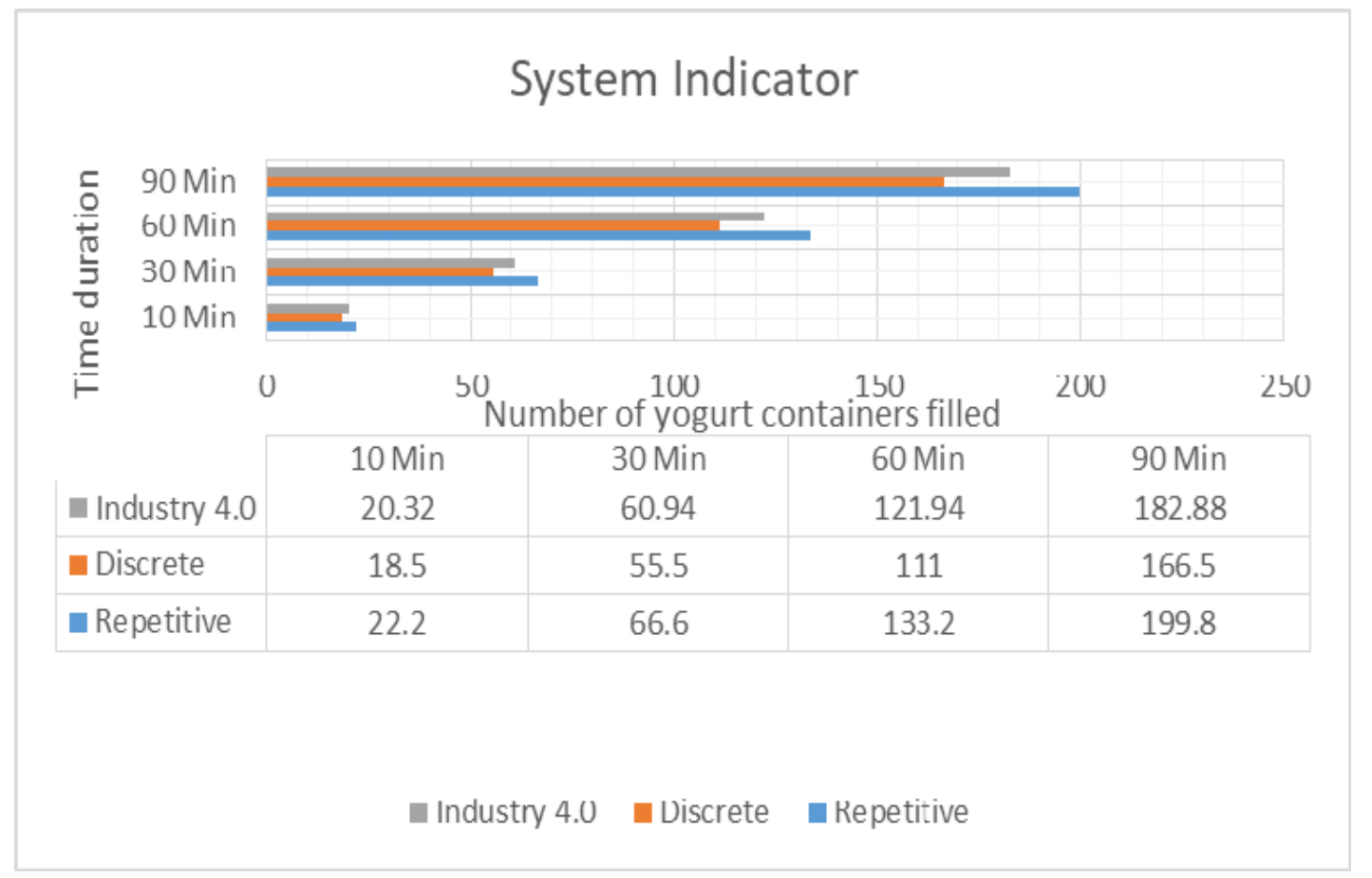

Fig. 4 Analysis of implememtion of different types of manufacturing processes

After implementing the Industry 4.0 concept the process time in manufacturing customised products according to customer demands decreased in comparison to the discrete type of manufacturing. The results also suggest that the performance improves when the Industry 4.0 concept is applied. This clear key performance index (KPI) in delivering a variety of products with absolute quantity assures mass customization. Our learning factory is programmed to be fully automated, so only filling the feeder tanks, stacking empty yogurt containers and removing them from the conveyor belt after the process is complete requires human intervention. Even this portion of manpower contribution is expected to be avoided in the next phase of development. 


\subsection{Smart design}

An essential component required for the conveyor system would have to have been manufactured using classical methods such as cutting, milling, lathing, drilling, and threading. This component was essential to allow the base plate in the conveyor system to run in a closed sequence. This serves as an excellent example of bottleneck failure, where a single hardware component can halt the whole production plant. To resolve such issues and to overcome such failures, a considerable investment is required. The effort taken by our research team to replicate a mechanical part of the conveyor system using a $3 \mathrm{D}$ printer is a noticeable initiative. Any conventional mechanical component damaged during operation or due to shear stress can be manufactured on-site. The use of the EnvisionTec Ultra 3SP (Fig. 5) 3D printing technology on-site to manufacture the few key mechanical components decreases the chance of a bottleneck failure in the production plant, especially operation related miscellaneous components. This approach to quickly correct faults caused by a failure of simple mechanical components raises corrective maintenance to a high level. Such recurring damaged components can be identified and their dimensions archived to avoid the redesign of a precision component, which is produced by using a high resolution printer.

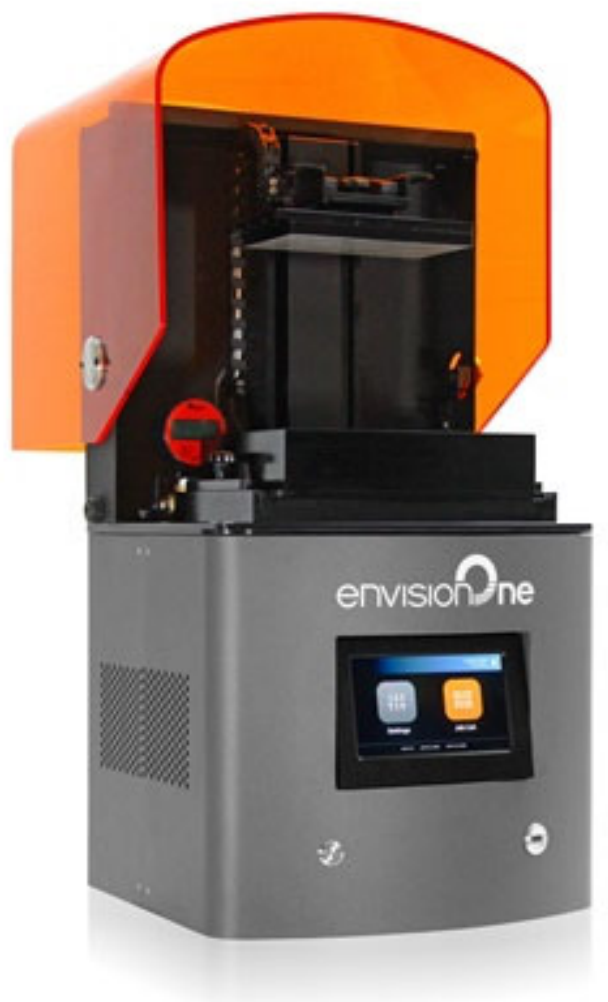

Fig. 5 EnvisionTec Ultra 3SP 3D printer (source: https://envisiontec.com)

\subsection{Smart monitoring}

As various sensors are deployed according to the requirement, the smart monitoring initiative was instigated. Although the sensors individually are not wireless or WiFiconnected at this phase, status reports of these sensors are obtained via web visualization, enabled via Wago PFC.

This graphical web visualization supports the monitoring of various functions and checks any abnormalities during the production phase of the flavoured yogurt. The controller 
is connected to the WiFi Router by Ethernet IP. It is an advantage that a monitoring PC connected wirelessly delivers information and status updates online. We realize the benefits of smart monitoring when we obtain precise data from sensors and product development status remotely.

\subsection{Smart control}

In Industry 4.0, high resolution, adaptive production control (i.e. smart control) can be achieved by developing cyber-physical production control systems [16]. Smart control of our production line in stage 1 was accomplished by using the Wago-WebVisu application. The application was installed in android devices to control the functions of the production line. Three important control function pushbuttons "ON," "OFF," and "EMERGENCY STOP" with defined global variable addresses were included in the program (Fig. 6). This means that end users can switch off a machine or robot via their smartphones [17]. This application gives convenient access to the control system, and we attempted to share data via the Message Queuing Telemetry Transport (MQTT) protocol. Using this, the establishment of the process synchronization is aimed, i.e. the exchange of data between multi-controllers from different vendors.

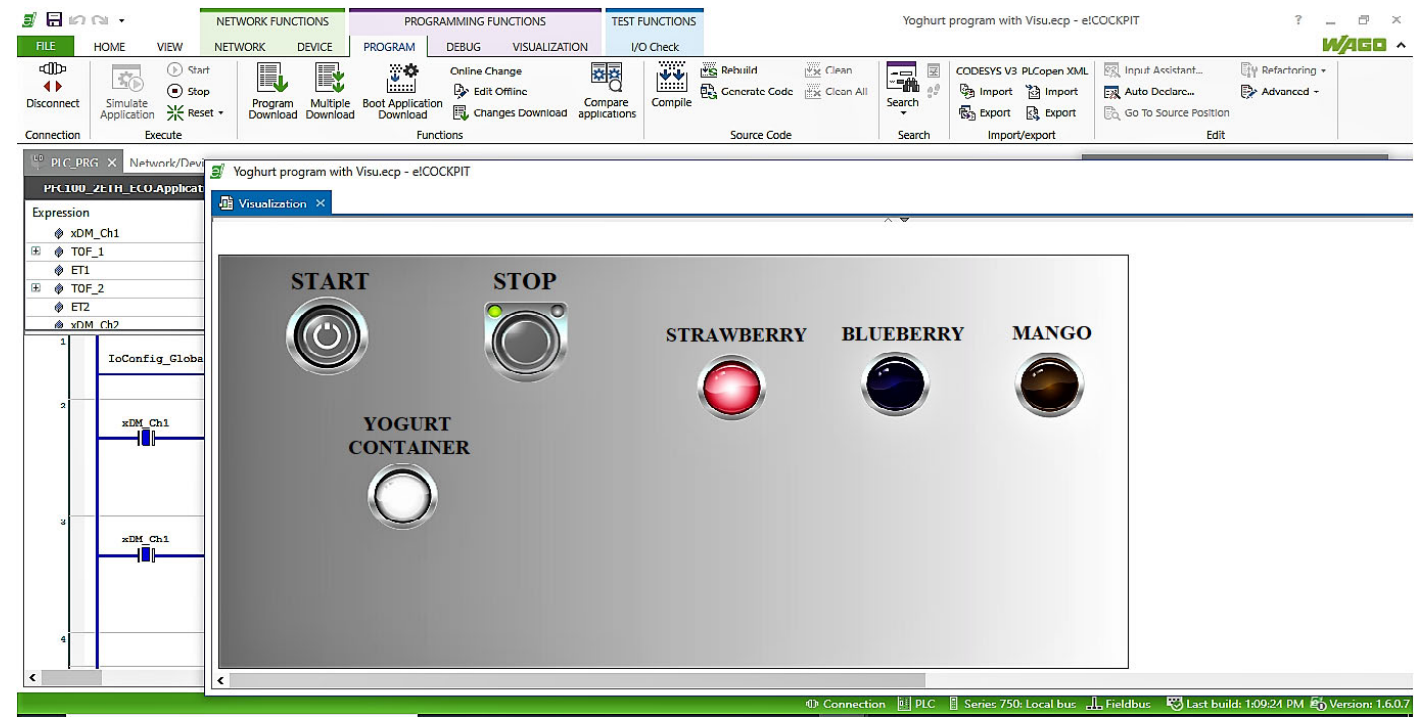

Fig. 6 Smart monitoring-enabled web-based management

\section{Conclusion and future work}

The presented interim goal, i.e. the building of a fully automated production line to deliver mass and customized smart products with cutting edge CPS and IoT technologies, is achieved. The objectives of the first stage are accomplished. The presented research has helped graduates from IED/KSU to improve their technical skills and has prompted them to develop innovative production techniques. Already at KSU, various departmental heads have offered their help and extended support to develop a concrete infrastructure for establishing an Industry $4.0 \mathrm{lab}$. In KSA, it is expected to have the backing of various SMEs, MSMEs and corporations after the mechanism presented in this paper is proposed for implementing I4.0 concept to help overcome hardware and other issues the companies may have. In the KSU, there will be more such orientation sessions to present the principles of Industry 4.0 to young graduates, so that they become familiar with the world trends and can lead our nation to fulfil the goals of "Vision 2030". The next phase will be the introduction of radio frequency 
identification (RFID) to be attached to the product to make it "smart". In addition, we aspire to add a Fanuc robotic arm to pick up the filled yogurt bottles and deliver them to the warehouse. All the results from stage 1, including the detailed specifications, key performance indicators (KPI), analysis of implementation, and precautionary programmes to avoid hazardous effects of the processing plant will be presented in an article yet to be published.

\section{Acknowledgment}

Researchers Supporting Project number (RSP-2019/145), King Saud University, Riyadh, Saudi Arabia.

\section{REFERENCES}

[1] Industry 4.0 document (English version): H. Kagermann, Wahlster, J. Helbig. Recommendations for implementing the strategic initiative INDUSTRIE 4.0. Heilmeyer und Sernau, Germany, 2013.

[2] KSA Vision 2030 Strategic Objectives and Vision Realization Programs. https://vision2030.gov.sa/sites/default/files/vision/Vision\%20Realization\%20Programs\%20Overview.pdf

[3] Buer, S. V.; Strandhagen, J. O.; Chan, F. T. S. The link between industry 4.0 and lean manufacturing: Mapping current research and establishing a research agenda, International Journal of Production Research 2018, 56 (8), 2924-2940, https://doi.org/10.1080/00207543.2018.1442945.

[4] Moeuf, A.; Pellerin, R.; Lamouri, S.; Tamayo-Giraldo, S.; Barbaray R. The industrial management of SMEs in the era of Industry 4.0, International Journal of Production Research 2018, 56 (3), 1118-1136, https://doi.org/10.1080/00207543.2017.1372647.

[5] Abele, E.; Metternich, J.; Tisch, M.; Reitberger T. Learning Factories: Concepts, Guidelines, BestPractice Examples, Springer, Cham 2018, https://doi.org/10.1007/978-3-319-92261-4_11.

[6] Jeschke, S.; Brecher, C. Meisen, T.; Özdemir, D.; Eschert, T. Industrial Internet of Things and Cyber Manufacturing Systems, In: Industrial Internet of Things. Springer Series in Wireless Technology. Springer, Cham 2017, https://doi.org/10.1007/978-3-319-42559-7_1.

[7] Burger, N.; Demartini, M.; Tonelli, F.; Bodendorf, F.; Testa, C. Investigating Flexibility as a Performance Dimension of a Manufacturing Value Modeling Methodology (MVMM): A Framework for Identifying Flexibility Types in Manufacturing Systems, Procedia CIRP 2017, 63, 33-38, https://doi.org/10.1016/j.procir.2017.03.343.

[8] Wang, Y.; Ma, H.-S.; Yang, J.-H.; Wang, K.-S. Industry 4.0: a way from mass customization to mass personalization production, Advances in Manufacturing 2017, 5, 311-320, https://doi.org/10.1007/s40436-017-0204-7.

[9] Salah, B.; Abidi, M. H.; Mian, S. H.; Krid, M.; Alkhalefah, H.; Abdo, A. Virtual reality-based engineering education to enhance manufacturing sustainability in industry 4.0, Sustainability 2019, 11 (5), 1477, https://doi.org/10.3390/su11051477.

[10] Bedolla, J. S.; D’Antonio, G.; Chiabert, P. A Novel Approach for Teaching IT Tools within Learning Factories, Procedia Manufacturing 2017, 9, 175-181, https://doi.org/10.1016/j.promfg.2017.04.049.

[11] ElMaraghy, H.; ElMaraghy, W. Learning Integrated Product and Manufacturing Systems, Procedia CIRP 2015, 32, 19-24, https://doi.org/10.1016/j.procir.2015.02.222.

[12] Schreiber, S.; Funke, L.; Tracht, K. BERTHA - A Flexible Learning Factory for Manual Assembly, Procedia CIRP 2016, 54, 119-123, https://doi.org/10.1016/j.procir.2016.03.163.

[13] Pittich, D. ; Tenberg, R.; Lensing, K. Learning factories for complex competence acquisition, European Journal of Engineering Education 2019, 1-18, https://doi.org/10.1080/03043797.2019.1567691.

[14] Kopetz, H. Real-Time Systems: Design Principles for Distributed Embedded Applications - Second Edition, Springer US 2011, DOI: 10.1007/978-1-4419-8237-7.

[15] Thramboulidis, K. IEC 61499 vs. 61131: A Comparison Based on Misperceptions, Journal of Software Engineering and Applications 2013, 6 (8), 405-415, https://doi.org/10.4236/jsea.2013.68050.

[16] Reiner, A. Industrie 4.0 - Advanced Engineering of Smart Products and Smart Production, Proceedings 19th International Seminar on High Technology Technological Innovations in the Product Development 2014 
[17] Wang, L. Machine availability monitoring and machining process planning towards Cloud, CIRP Journal of Manufacturing Science and Technology 2013, 6 (4), 263-273, https://doi.org/10.1016/j.cirpj.2013.07.001.

Submitted: $\quad 03.02 .2020$

Accepted: $\quad 11.3 .2020$
Asst. prof. Bashir Salah

Department of Industrial Engineering,

College of Engineering, King Saud

University, P.O. Box 800, Riyadh 11421

Saudi Arabia

bsalah@ksu.edu.sa

Eng. Sajjad Khan

Supervising Electronics Engineer, Saudi BinLadin Group,

Kingdom of Saudi Arabia

Asst. prof. Nikola Gjeldum

Faculty of Electrical Engineering,

Mechanical Engineering and Naval Architecture, University of Split, R. Boskovica, 32, Split, Croatia 